\title{
Keratin 17 null mice exhibit age- and strain-dependent alopecia
}

\author{
Kevin M. McGowan, ${ }^{1,4}$ Xuemei Tong, ${ }^{1,4}$ Emma Colucci-Guyon, ${ }^{3}$ Francina Langa, ${ }^{3}$ Charles Babinet, ${ }^{3}$ \\ and Pierre A. Coulombe $1,2,5$ \\ ${ }^{1}$ Departments of Biological Chemistry and ${ }^{2}$ Dermatology, Johns Hopkins University School of Medicine, Baltimore, \\ Maryland 21205, USA; ${ }^{3}$ Unité de Biologie du Développement, URA 1960, CNRS-Institut Pasteur, \\ 75724 Paris CEDEX 15, France
}

\begin{abstract}
Onset of type I keratin 17 (K17) synthesis marks the adoption of an appendageal fate within embryonic ectoderm, and its expression persists in specific cell types within mature hair, glands, and nail. We report that K17 null mice develop severe alopecia during the first week postbirth, correlating with hair fragility, alterations in follicular histology, and apoptosis in matrix cells. These alterations are incompletely penetrant and normalize starting with the first postnatal cycle. Absence of a hair phenotype correlates with a genetic strain-dependent compensation by related keratins, including K16. These findings reveal a crucial role for K17 in the structural integrity of the first hair produced and the survival of hair-producing cells. Given that identical inherited mutations in this gene can cause either pachyonychia congenita or steatocystoma multiplex, the features of this mouse model suggest that this clinical heterogeneity arises from a cell type-specific, genetically determined compensation by related keratins.
\end{abstract}

[Key Words: Keratin; skin; hair; nail; gland; pachyonychia congenita; steatocystoma multiplex]

Received January 25, 2002; revised version accepted April 19, 2002.

Understanding how complex cellular mosaics such as hair follicles, nail, and glands are formed during skin embryogenesis and maintained in adult life presents a formidable task and has implications for a variety of skin disorders, including neoplasias. At least seven programs of terminal epithelial differentiation are coordinated and integrated to give rise to a hair-producing follicle that undergoes a growth cycle throughout life. Complex epithelial-mesenchymal interactions play a crucial role throughout the development and subsequent homeostasis of hair and other epithelial appendages (Oro and Scott 1998; Paus and Cotsarelis 1999; Fuchs et al. 2001).

It is in this context that the type I intermediate filament protein keratin 17 (K17) is first synthesized at an early stage of cell fate specification within developing skin epithelia. Onset of K17 synthesis marks the adoption of an appendageal fate within mouse embryonic ectoderm, and likely occurs in response to a Wnt signal (McGowan and Coulombe 1998a). As appendageal precursors evolve into mature hair follicles, nail, and glands, the expression of $K 17$ becomes restricted to a subset of specialized cell types (McGowan and Coulombe 1998a, 2000). K17 stands out among type I keratin genes in that it is expressed in both soft and hard epithelial tissues, and uses different type II keratins as poly-

\footnotetext{
${ }^{4}$ These authors contributed equally to this work.

${ }^{5}$ Corresponding author.

E-MAIL coulombe@jhmi.edu; FAX 410-614-7567.

Article and publication are at http://www.genesdev.org/cgi/doi/10.1101/ gad.979502.
}

merization partners (e.g., K6, K5, K7). In addition to this constitutive component involving epithelial appendages and other epithelia (Troyanovsky et al. 1989; McGowan and Coulombe 1998b), the K17 gene is induced following injury or in disease contexts (e.g., viral infection, carcinoma, psoriasis; Markey et al. 1992; Proby et al. 1993; Jiang et al. 1994; Leigh et al. 1995; Grachtchouk et al. 2000). Inherited mutations in K17 give rise to two distinct disorders, type 2 pachyonychia congenita (OMIM 167212) and steatocystoma multiplex (OMIM 184500; for review, see Irvine and McLean 1999). These disorders are related to ectodermal dysplasias (Feinstein et al. 1988), and while they affect primarily the nail and sebaceous glands, respectively, hair anomalies are also seen. Elucidating the function of K17 may thus provide significant insights into our understanding of the morphogenesis, differentiation, and homeostasis of epithelial appendages.

Also of interest is the issue of keratin protein function in epithelial cells and tissues. Type I and type II keratin genes, each numbering 25 in the human genome (Hesse et al. 2001), are differentially regulated in a pairwise fashion in the various epithelia making up the body, and the corresponding proteins heteropolymerize to form a pancytoplasmic intermediate filament (IF) network. Given their properties, abundance, and organization in epithelial cells and tissues, keratin IFs are poised to play an important role of mechanical support (Ma et al. 2001). Accordingly, inherited mutations affecting keratin genes underlie a variety of epithelial fragility conditions (Fuchs and Cleveland 1998; Irvine and McLean 1999; Coulombe 
and Omary 2002). In addition to this family-wide role, keratin filaments fulfill cell type- and context-dependent functions that include protection against metabolic stress, modulating the response to apoptotic signals, progression through the cell cycle, and promotion of specific epithelial cytoarchitecture (Coulombe and Omary 2002). Despite significant recent progress, however, our understanding of the relationship between keratin proteins and the differentiated epithelial phenotype remains deficient. To address the issue of K17 function in vivo, we inactivated the $K 17$ locus in mouse via gene targeting and homologous recombination. Here we describe the peculiar hair phenotype that arises in a genetic straindependent fashion in $K 17$ null mice, and discuss the implications for $\mathrm{K} 17$ function and role in disease.

\section{Results}

K17 null mice exhibit severe alopecia in an ageand strain-dependent fashion

The linearized K17 targeting vector (Fig. 1A) was introduced in the $129 / \mathrm{Sv}$ CK35 embryonic stem (ES) line (Kress et al. 1998). Of 480 drug-resistant ES clones, three were positive for homologous recombination upon Southern blot analysis and PCR. Two correctly targeted lines, designated $\mathrm{A}$ and $\mathrm{B}$, gave rise to germ-line transmission in a $129 / \mathrm{Sv}-\mathrm{C} 57 \mathrm{Bl} / 6-\mathrm{DBA} 2$ mixed background (see Materials and Methods). To generate mice that are homozygous for the targeted allele, $\mathrm{K} 17^{+/-}$males and females were mated. The targeted allele segregated in a Mendelian fashion as shown by Southern blot analysis of genomic DNA (Fig. 1B). In adult back skin, the K17 mRNA $(\sim 1.7 \mathrm{~kb})$ is reduced by half in hemizygous null mice and is completely absent in samples from $\mathrm{K} 17^{-/-}$ mice (Fig. 1C). Reprobing the stripped membrane with a probe specific for $\mathrm{Neo}^{\mathrm{r}}$ yielded strong hybridization to a single band of the correct size $(\sim 1.3 \mathrm{~kb})$ in $\mathrm{K}^{-7^{+/}}$and especially in $\mathrm{K}_{17^{-/-}}$samples (Fig. 1C). In protein extracts prepared from several tissues including hair clippings (Fig. 1D), the K17 antigen is completely absent in $K 17^{-/-}$ samples but occurs at wild-type levels in $\mathrm{K} 7^{+/-}$samples. No immunoreactivity for K17 can be detected in sections prepared from $K 17^{-/-}$tissues, including dorsal tongue (Fig. 1E). Identical data were obtained in lines A and B. Together these analyses establish that mice homozygous for the targeted allele do not express the K17 mRNA or protein, and are viable.

Pups born from matings involving $\mathrm{K} 7^{+/-}$mice in the original mixed strain background (designated first generation or F1) appear normal at birth. All newborn pups feed and grow normally. Within a few days, however, a

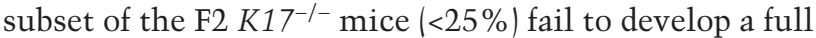
coat of hair. The severity of alopecia is variable in both lines A and B (a severe case is shown in Fig. 1F). All phenotypic mice are $\mathrm{K}_{17^{-/-}}$. The variable penetrance of alopecia does not correlate with any peculiarity at the genomic DNA or RNA level. To explore the possibility that the occurrence and severity of the skin phenotype is the result of modifier allele(s) that would function in a strain-dependent fashion, we set up multiple matings in- volving F2 phenotypic $K 17^{-/-}$males and females. This led to a marked increased frequency of the alopecia condition within the F3 progeny. Some of the mating pairs, in fact, consistently produced only phenotypic mice. Further examination of the $K 17^{-/-}$mice exhibiting severe alopecia showed that vibrissae were often missing on either side of the nose, but the examination failed to reveal obvious anomalies at a gross level in the nail (data not shown).

These observations were suggestive of a strain effect modulating the impact of the K17 null mutation in mouse. To identify which strain backgrounds are permissive and nonpermissive for the hair phenotype, we set out to transfer the null allele to each of the $129 / \mathrm{Sv}$ and $\mathrm{C} 57 \mathrm{Bl} / 6$ inbred strain backgrounds (see Materials and Methods). Up to 6 months of age, no $K 17^{-/-}$mice exhibit a detectable skin phenotype in the $129 / \mathrm{Sv}$ background. In striking contrast, and after backcrosses over six generations, all of the $K 17^{-/-}$mice in the C57Bl/6 background exhibit a phenotype similar to that shown in Figure 1F. A genetic strain effect in the penetrance of the phenotype associated with null mutations in other keratin genes, including $K 8$ (Baribault et al. 1994) and $K 6 \alpha /$ K6 $\beta$ (Wong et al. 2000; Wojcik et al. 2001), has been described. Of note, K6 isoform proteins act as a polymerization partner for K17 in several but not all cell types in which it is expressed (McGowan and Coulombe 1998a; Takahashi et al. 1998). The variable penetrance of the K17 null phenotype in mouse is also intriguing in light of the phenotypic variability seen in patients whose genomes harbor missense mutant K17 alleles (see Discussion).

\section{Hair fragility and apoptosis in hair-producing tissue contribute to the alopecia phenotype}

Morphological analyses were conducted to define the nature of the alterations affecting K17 null skin. In rostrocaudal sections of back skin, the entire length of anagenstage hair follicles can be appreciated (Fig. 2A). In wildtype or $\mathrm{K} 7^{+/-}$skin, the K17 antigen is typically detected in the outer root sheath, the medulla of the hair shaft, and the matrix (Fig. 2A, inset; see also McGowan and Coulombe 1998). In similar sections prepared from agematched phenotypic $K 17^{-/-}$skin, the K17 antigen is completely missing (data not shown) and several hair follicle profiles show a variety of anomalies (Fig. 2B,C). Typical alterations seen in all sections examined include the presence of large aggregates of melanin pigments at various points along the length of the follicles, obvious signs of cellular degeneration (see below), and the slightly shorter length of the follicles (Fig. 2A-C). Under higher magnification, cellular degeneration can be seen in all the mature compartments of the hair follicle, including the outer and inner root sheaths (Fig. 2D,E), and the hair shaft (Fig. 2F). Unusual breaks or rupture in the hair shaft can be seen above the bulb region (Fig. 2F). Also of significance, the epithelial cells of the matrix within hair bulbs undergo massive destruction in a small subset of hair follicles (Fig. 2, cf. G and H) owing to apoptosis, as confirmed by a positive reaction following 
Figure 1. Generating $K 17^{-/-}$mice. $(A)$ Targeting strategy used to inactivate the $K 17$ locus. A $3.0 \mathrm{~Kb}$ AatII-EcoRI fragment (5'side) and a $4.5 \mathrm{~Kb} \mathrm{XbaI}$ fragment ( 3 'side; see Materials and Methods) were subcloned on either side of a Neo ${ }^{r}$ cassette in plasmid NeoTKXho. Homologous recombination removes the proximal promoter, exons $1-4$ and part of exon 5, and the intervening introns in the K17 gene. A, AatII; RI, EcoRI; RV, EcoRV; S, AseI; X, $X b a I$. This schematic is not drawn to scale. $(B)$ Southern blot analysis on AseI/EcoRV-digested genomic DNA (5' side of the locus) reveals a 4.5 $\mathrm{kb}$ and a $3.7 \mathrm{~kb}$ band corresponding to wild-type and recombined alleles, respectively. Homologous recombination was confirmed on the 3 'side following $\mathrm{XbaI}$ digestion (wt allele: $8.8 \mathrm{~kb}$ product; targeted allele: $4.6 \mathrm{~kb}$; data not shown). Probe location is depicted with cross-hatched bars. These findings were confirmed by PCR assays using primer located inside and outside the targeting vector (data not shown). (C) Northern blot analysis was performed on total RNA $(10 \mu \mathrm{g})$ extracted from back skin using probes specific for either the $3^{\prime}$ end of $\mathrm{K} 17$ or $\mathrm{Neo}^{\mathrm{r}}$. The top gel is ethidium bromide-stained to visualize total RNA levels. $(D)$ Western blot analysis. Proteins were isolated from hair clippings, resolved via SDS-PAGE, transferred onto nitrocellulose membrane, and reacted with a rabbit antiserum to K17. Quasinormal levels of $\mathrm{K} 17$ antigen are seen in $\mathrm{K} 7^{+/-}$samples, whereas no product was detected in $K 17^{-1-}$ samples. $(E)$ Peroxidase-based immunolocalization of K17 antigen in cross-sections prepared from paraffin-embedded dorsal tongue epithelium (A-P axis). A strong signal for K17 was detected in the anterior and buttress columns of the filiform papillae (fp) in $\mathrm{K} \mathrm{7}^{+/-}$but not in $\mathrm{K} 17-/-$ samples. Bar, $200 \mu \mathrm{m}$. (F) Phenotypic appearance of $K 17^{-/-}$(left) and $\mathrm{K} \mathrm{7}^{+/-}$(right) littermates at $21 \mathrm{~d}$ postbirth.
$\mathbf{A}$

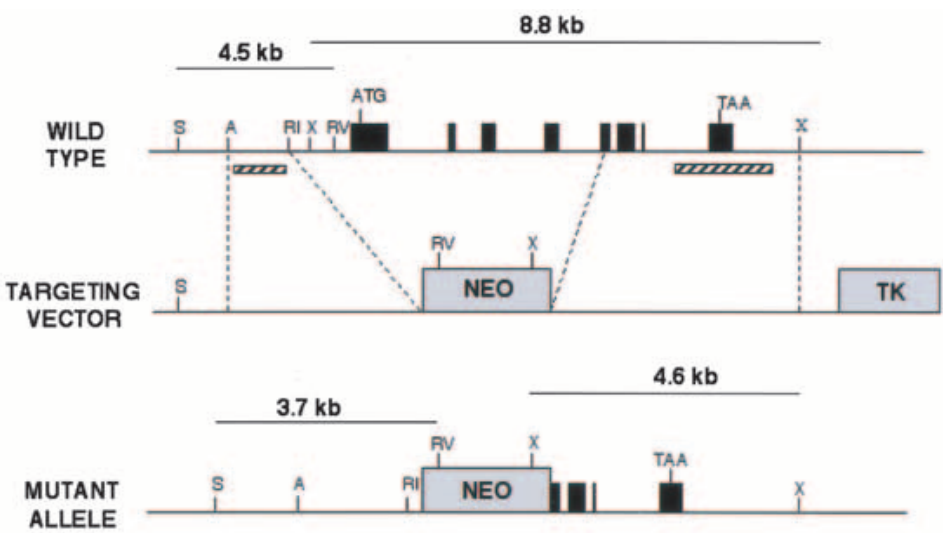

B

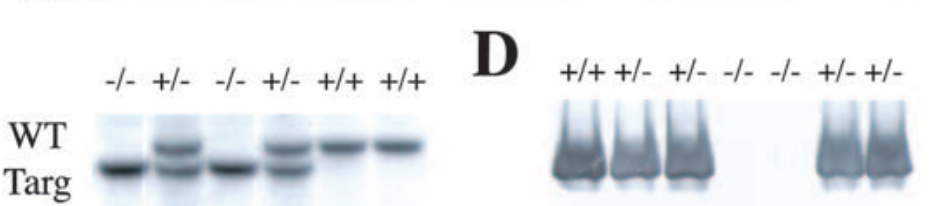

C
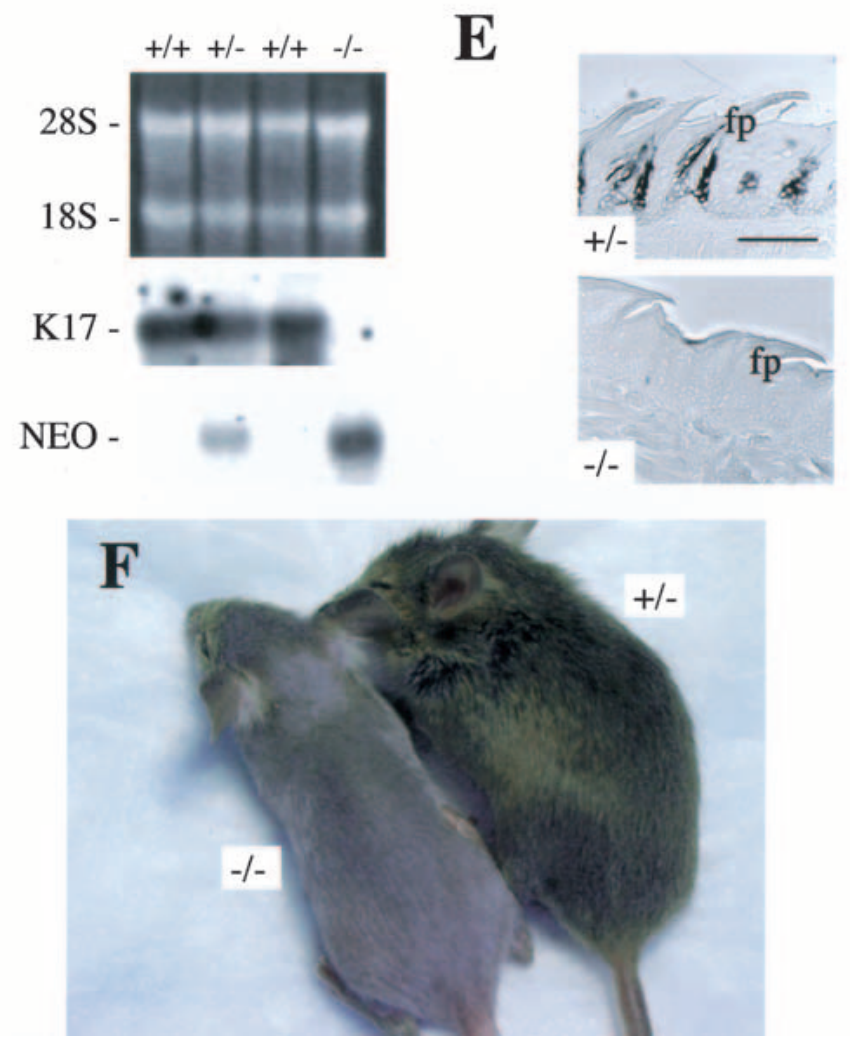

in this assay (Fig. 2K). The frequency of all types of follicular alterations is much enhanced at $7 \mathrm{~d}$ and especially at $10 \mathrm{~d}$ postbirth. The occurrence of visible breaks in the hair shaft inside the follicular sleeve (Fig. 2F) and the melanin pigment aggregates, which may likely ensue hair shaft destruction (Fig. 2B,C), suggest that hair fragility represents an early alteration in $K 17^{-/-}$hair follicles. In addition, a subset of $\mathrm{K} \mathrm{7}^{-/-}$hair bulbs exhibit an unusual ovoid body consisting of multiple eosinophilic matrix epithelial cells located most frequently $(>88 \%$ of cases) on their posterior aspect (Fig. 2L). Similar sized 


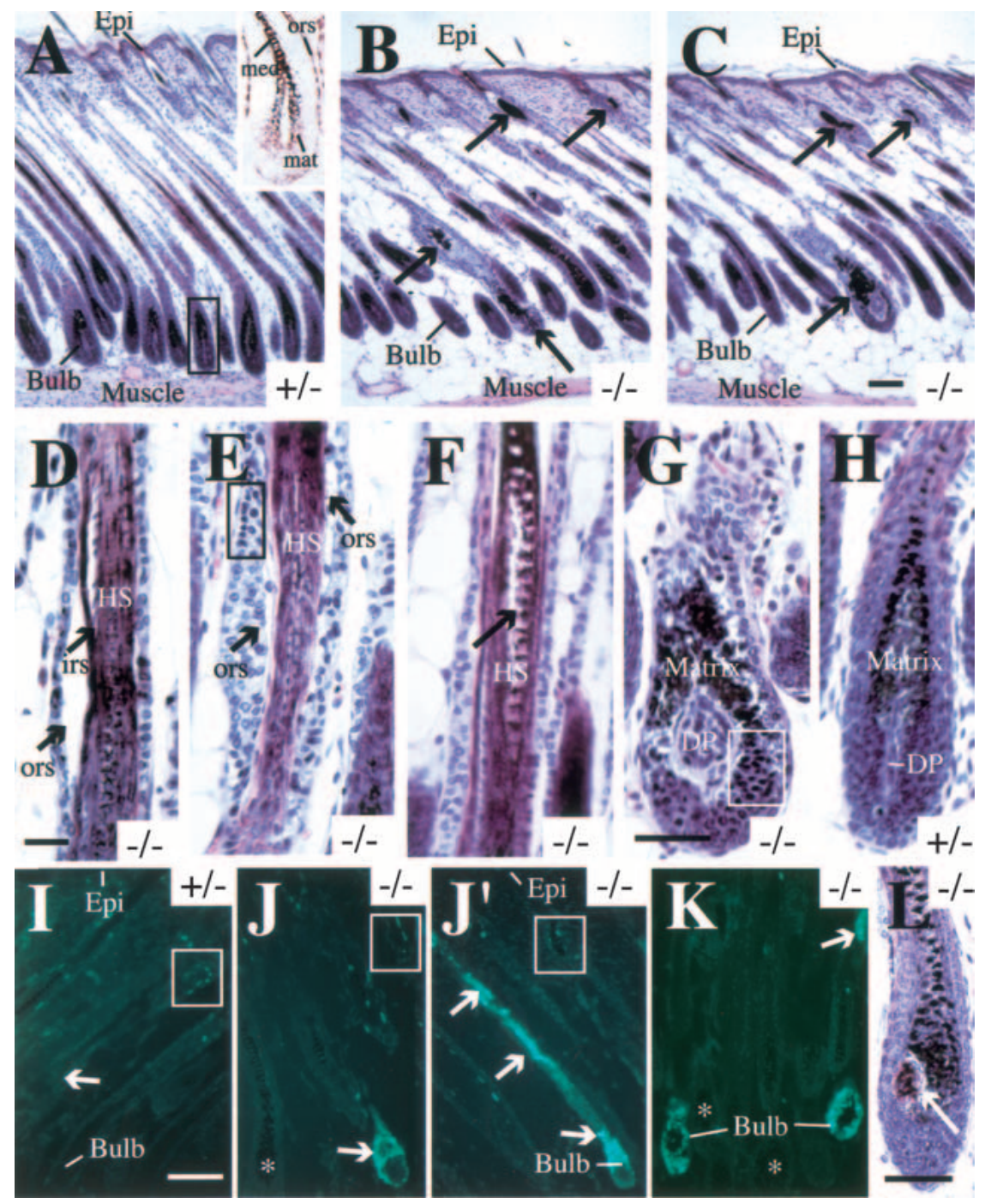

Figure 2. Morphological characterization of $\mathrm{K}_{17^{-/-}}$skin. Back skin tissue was harvested, fixed, and paraffin-embedded, and cross-sections along the cephalocaudal axis were counterstained with hematoxylin-eosin $(A-H, L)$ or processed for TUNEL staining to detect apoptotic cells $(I-K)$. All tissues were obtained from 5-, 7- or 10day-old mice as indicated. $(A-C)$ Low-magnification survey of the entire thickness of 7-day-old skin, ranging from the epidermis at the surface (Epi) to the panniculus carnosus (muscle) layer at the bottom end of the tissue. Compared to $\mathrm{K}_{1} 7^{+/-}$skin, where hair follicle profiles are long and display a regular architecture and healthy looking bulb region $(A)$, the follicular profiles are shorter in $K 17^{-1-}$ mice $(B, C)$. Obvious anomalies are present in a subset of hair follicles, easily detected as large melanin pigment aggregates located at various points along the follicles (arrows). The inset in $A$ shows the distribution of K17 antigen in the bulb region of the hair (see boxed area in $A$ ) in a frozen section prepared from 13-day-old wt mouse skin. Positive staining is seen in the matrix (mat), the medulla of the hair shaft (med), and the outer root sheath (ors). $(D-H)$ Higher-magnification view of alterations

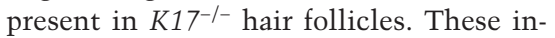
clude: $(D)$ Premature separation (arrows) of the outer root sheath (ORS) and inner root sheath (IRS) layers from the hair shaft (HS) in this 10-day-old $\mathrm{K}^{17^{-/-}}$sample; $(E)$ Obvious cytolysis (arrows) and pyknotic nuclei (boxed area ) within the ORS epithelium in this 10 -day-old $K 17^{-/-}$sample; $(F)$ rupture of the hair shaft within the medulla compartment (arrow) in this 7-day-old $\mathrm{K}^{-7^{-/}}$ sample. Cellular degeneration and pyk-
lb $\left(G\right.$; 10-day-old $\left(K 17^{-l-}\right)$, something that is

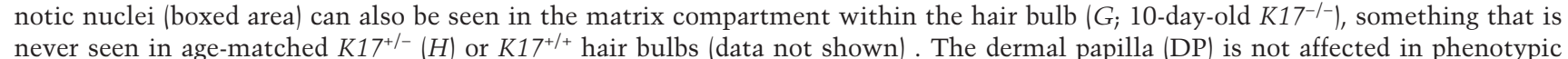
$K 17^{-/-}$tissue (cf. $G$ and $\left.H\right)$. $(I-K)$ Detection of apoptotic cells through TUNEL staining in 7-day-old skin samples. In $K 17^{+/-}(I)$ as in $K 17^{+/+}$samples (data not shown), a small subset of flat nuclei near the isthmus compartment are TUNEL-positive (boxed area). In phenotypic $\mathrm{K} 17^{-/-}$samples, however, massive apoptosis is seen to occur in the bulb region of some hairs $(J)$, whereas other hair profiles show TUNEL-positive nuclei all along their length $\left(J^{\prime}\right)$. Even in this instance, however, many hairs show normal TUNEL staining (see asterisk in $J$ ). At $5 \mathrm{~d}$ postbirth, TUNEL-positive nuclei are most frequently seen in the matrix of the hair bulb $(K)$. $(L)$ Bulb region in a 7-day-old $K 17^{-/-}$mouse. The arrow points to an unusual multicellular ovoid body within the hair bulb. Bar in $C, 100 \mu \mathrm{m}$ and applies for $A-C$; bar in $D, 100 \mu \mathrm{m}$ and applies for $D-F$; bar in $G, 50 \mu \mathrm{m}$ and applies for $G-H$; bar in $I, 100 \mu \mathrm{m}$ and applies for $I-K$; bar in $L, 75 \mu \mathrm{m}$.

bodies occur at a comparable frequency in both phenotypic and nonphenotypic $K 17^{-/-}$skin $(\sim 20 \%$ of hair bulb profiles), but never in $K 17^{+/-}$or $K 17^{+/+}$skin. This said, their frequency peaks significantly more early in phenotypic (i.e., at $7 \mathrm{~d}$ postbirth) than in nonphenotypic (10 d postbirth) $K 17^{-/-}$skin. Immunolocalization of various markers of keratinocyte differentiation in the epidermis and hair follicles revealed no other anomalies, except for enhanced staining for K16 in the outer root sheath of hair follicles showing histological aberrations (data not shown), a finding typical of lesions affecting this tissue. These observations establish that while abrogation of K17 expression does not impair either morphogenesis or differentiation within skin epithelia, it causes severe structural alterations in all major compartments of the hair follicle, starting a few days postbirth.

Four major types of hair (zigzag, guard, awl, auchene) occur on the body of mice, each with a characteristic frequency (Sundberg and Hogan 1994). Analysis of plucked hair samples failed to reveal differences at that level between phenotypic $K 17^{-/-}$and control mice (data not shown). During this analysis, we noticed that hairs isolated from phenotypic $K 17^{-/-}$mice are prone to break when manipulated. To examine this further, intact zigzag hairs were isolated from $K 17^{+/-}$and phenotypic $\mathrm{K} 17^{-/-}$mice and subjected to a pulling assay to assess 
mechanical resilience. The $K 17^{-/-}$hairs were threefold more likely to break when pulled compared to $\mathrm{K} 17^{+/-}$ ones, confirming that they are more fragile. Plucked hairs were also analyzed using scanning electron microscopy. Control $\mathrm{K}_{17^{+/-}}$mouse hairs show the typical imbricated shingle pattern created by the serial overlapping of cuticle layer cells at the hair surface (Fig. 3A). In contrast, $\mathrm{K} 17^{-/-}$null hairs frequently exhibit defects, including cracks on their side (Fig. 3B) and complete breaks (Fig. 3C). Analysis of ultrathin sections prepared from 5-day-old mouse skin by transmission EM revealed the occurrence of cell lysis and pyknotic nuclei within the matrix of the bulb (Fig. 3, cf. D and $\mathrm{D}^{\prime}$ ) and in the lower medulla compartment in a subset of hair follicle profiles. In addition, outer root sheath keratinocytes often display a swollen and electronlucent appearance compared to controls (Fig. 3D and $\mathrm{D}^{\prime}$ ). In contrast, matrix-embedded melanocytes appear intact (Fig. 3D), indicating the cell type specificity of the lesions. Together, these findings are consistent with the notion that the absence of K17 protein causes the hair initially produced to be fragile and prone to apoptosis, possibly owing to defects in the medulla and matrix compartments, where the protein normally occurs (Fig. 2A).

The alopecia condition normalizes starting with the onset of postnatal cycling

Remarkably, even the most severely phenotypic $K 17^{-/-}$ mice show a dramatic improvement of the fur phenotype after three weeks of age. Phenotypic recovery peaks at 30 days or so in the mixed strain background in which the $\mathrm{K} 17^{-/-}$animals were originally obtained (Fig. 4A-D). Recovery occurs with similar timing in the C57Bl/6 background as well. This coincides with the onset of the first postnatal anagen phase of the hair cycle at approximately three weeks after birth (Sundberg and Hogan 1994). Histologically, recovery correlates with a reduced frequency of abnormal hair follicle profiles, although these clearly persist in samples harvested from 27-dayold mice (Fig. 4E). Finally, examination of body sitematched skin samples from 31-day-old mice show that individual hair follicles are often at different phases of their cycle in $\mathrm{K}_{17^{-/-}}$compared to either $\mathrm{K} 17^{+/+}$or $\mathrm{K} 17^{+/-}$ skin (Fig. 4F,G). This suggests that the null allele impacts progression through the hair cycle. These findings extend a number of recent reports pointing to the existence of important differences between the initial phase of hair morphogenesis, growth, and differentiation, which begins at mid-stage of embryogenesis and extends to three weeks postnatally, and subsequent cycling of the hair (Gat et al. 1998; Sano et al. 2000). They also imply that for most hair follicles, the wave of apoptosis that takes place between days 5 and 10 after birth in phenotypic $\mathrm{K} 17^{-/-}$mice does not fully impair the ability of stem cells to give rise to a new anagen hair.

\section{Compensatory increases in related type I keratins likely modulate the K17 null phenotype}

Along with the lack of obvious anomalies in other epithelial appendages (e.g., nail, gland; see below), the
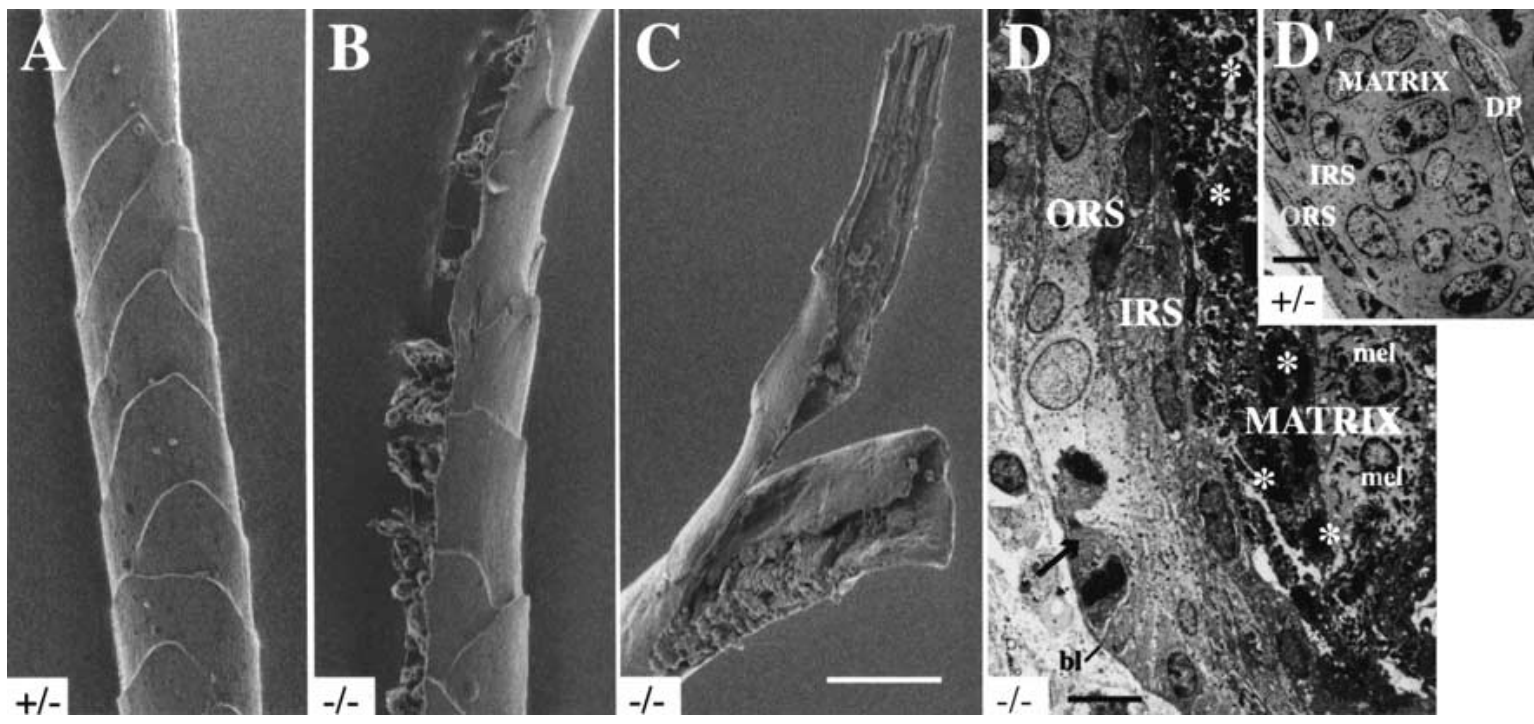

Figure 3. Ultrastructural alterations in hair tissue in $K 17^{-/-}$mouse skin. $(A-C)$ Visualization of the surface features of zigzag hairs, isolated from 14-day-old mice, using scanning electron microscopy (see Materials and Methods). Compared to $\mathrm{K} 17^{+/-}(A)$ or $\mathrm{K} 17^{+/+}$hair (data not shown), hairs plucked from phenotypic $K 17^{-/-}$mice show multiple types of structural aberrations, including rupture on their lateral surface (see $B)$ and complete break with fraying of extremities (see $C)$. Bar in $C, 10 \mu \mathrm{m}$ and applies for $A-C$. $\left(D-D^{\prime}\right)$ Visualization of the ultrastructure of the hair bulb in 5-day-old trunk skin using transmission EM of thin resin sections (see Materials and Methods). In the $K 17^{+/-}$hair bulb shown $\left(D^{\prime}\right)$, all the epithelial cells of the matrix appear healthy, with a large nucleus and a high nucleocytoplasmic ratio characteristic of rapidly dividing cells. Epithelial cells of the outer and inner root sheaths (ORS and IRS, respectively) exhibit a typical flat appearance. In the $K 17^{-/-}$hair bulb sample shown in $D$, many pyknotic nuclei can been seen in the matrix (asterisks). In contrast, melanocytes (mel) appear normal. Many epithelial cells within the ORS are swollen and their cytoplasm is unusually electronlucent (the arrow points to a late mitotic figure). DP, dermal papilla; bl, basal lamina. Bars, $5 \mu \mathrm{m}$. 


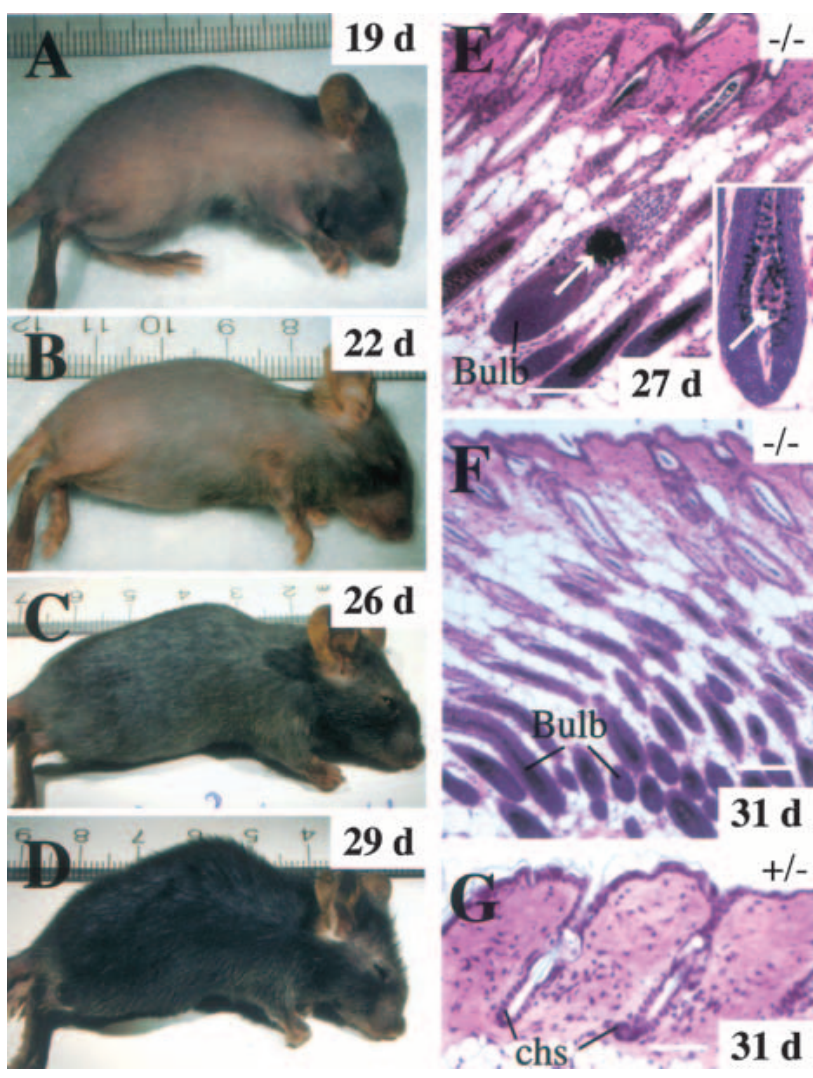

Figure 4. The alopecia phenotype improves with age in $\mathrm{K} 17^{-/-}$ mice. $(A-D)$ A phenotypic $K 17^{-I-}$ mouse was photographed over the course of a 10-d period (age is indicated in the upper right corner). Coinciding with the onset of the first postnatal anagen phase of the hair cycle at $\sim 3$ wk after birth, a fur covering progressively emerges on the trunk of this mouse. This example is representative of many but not all phenotypic $\mathrm{K} 17^{-/-}$mice. (EG) Histology of back skin of recovering phenotypic $K 17^{-/-}$mice (paraffin-embedded sections, hematoxylin-eosin staining). (E) Significant alterations persist in a small subset of hair follicles in a recovering 27 -day-old $\mathrm{K}_{17^{-/-}}$mouse. The arrow points to a large aggregate of melanin pigments in a degenerating hair follicle, and the inset shows the presence of an unusual multicellular ovoid body in the hair bulb (arrow; see also Fig. 2L). $(F, G)$ Hair cycle anomalies persist in recovering $\mathrm{K} 17^{-/-}$mice compared to a $\mathrm{K} 7^{+/-}$littermate at $3 \mathrm{~d}$ of age. In these skin sections prepared from the same region of the back, individual follicles are in the anagen (growth) stage of the hair cycle in the $\mathrm{K}^{1} 7^{-/-}$ mouse, as evidenced by the presence of a bulb structure, whereas they are in the telogen stage in the $\mathrm{K} 7^{+/-}$mouse. Chs, club hair sheath. Bars, $100 \mu \mathrm{m}$.

strain-dependence of the alopecia condition and its recovery with the first postnatal hair cycle suggest that the impact of the K17 null allele is mitigated by other factors, possibly modifier genes. Keratins 14 and 16 are legitimate candidates for this purpose, given that they are both related to K17 at the levels of primary structure and distribution within complex epithelia (McGowan and Coulombe 1998a). In addition, the K16 gene is often induced when complex epithelia are challenged (McGowan and Coulombe 1998b). The steady-state levels of these keratin antigens were determined by Western blot analysis of protein extracts prepared from hair clippings (implying no contamination by soft skin tissue), taking into account the age and strain background of the animals. No K14 immunoreactivity could be detected in such hair protein extracts (data not shown). In samples prepared from 33-35-day-old mice (reflective of the second hair produced by hair follicles; Sundberg and Hogan 1994), we discovered that the K16 antigen levels are strikingly higher in $K 17^{-/-}$mice than littermate controls for both the C57Bl/6 and 129 Sv strain backgrounds (Fig. $5 \mathrm{~A})$. In the $\mathrm{C} 57 \mathrm{Bl} / 6$ strain background, increased K16 levels also occurred in $\mathrm{K}_{17^{+/-}}$samples, though to a lesser extent (Fig. 5A). No obvious change was detected in the general protein profile, as shown by Coomassie blue staining (Fig. 5A). The extent of the K16 level increase seen in $\mathrm{K}_{17^{-/-}}$samples is comparable in the two inbred strain backgrounds, and correlates with a normalization of the alopecia condition in 33-35-day-old C57Bl/6 mice (similar to the examples provided in Fig. 4A-D) and the full fur covering shown by $129 \mathrm{~Sv}$ mice. Next we investigated K16 antigen levels in similar samples prepared from 14-day-old mice, which is reflective of the first hair produced by individual follicles. We found that while K16 is barely detectable under our conditions in hair proteins from wild-type or $K 17^{+/-} 129$ Sv mice, its levels are dramatically elevated in samples taken from $K 17^{-/-}$ mice (Fig. 5B), which do not exhibit alopecia in this strain background. The levels of K16 are comparatively higher in 14-day-old wild-type $\mathrm{C} 57 \mathrm{Bl} / 6$ mice, but they increase relatively modestly in $\mathrm{K}^{7^{+/-}}$and $\mathrm{K} 17^{-/-}$hair samples (Fig. 5B). It should be noted that the $K 17^{-/-}$ C57Bl/6 mice are severely phenotypic at this age, and protein samples were prepared from hair that had survived the destruction brought about by the K17 null mutation. Immunohistochemical analyses were conducted to expand on these biochemical findings. In mature hair follicle profiles, K16 normally localizes to the innermost layer of the outer root sheath (the so-called companion layer) and the medulla, but is not normally detected in the matrix (Fig. 5C; see also K. Bernot, K. McGowan, and P.A. Coulombe, in prep.). In sections prepared from nonphenotypic $\mathrm{K}_{17^{-/-}}$mice in the original mixed strain background, K16 staining is not only enhanced in the medulla, it is also clearly visible in the matrix compartment (see double arrows in Fig. 5D). This phenomenon is not observed for K6 (data not shown), the most frequent type II partner for K16 in epithelial cells. Collectively, these analyses establish that the steady-state levels of K16 antigen in hair tissue, and the ability to increase them in response to the absence of K17, differ between strains of mice and possible between hair cycles. They also suggest that a compensatory increase in K16 modulates the impact of K17 null mutation on the hair tissue. From the data collected from 14-day-old mice (see Fig. $5 \mathrm{~B})$, and given that the protein makeup of hair clippings is a reflection of protein synthesis that took place several days earlier, we surmise that the timing and/or extent of this induction, rather than steady-state levels of K16 achieved, may represent the most relevant factor in this protective effect. 
Figure 5. Up-regulation of the related type I keratin 16 likely mitigates alterations in epithelial appendages in an age- and strain-dependent fashion in K17 null skin. (A) Western analysis of total protein extracts of hair clippings from 33-35-day-old mice, which corresponds to the second hair being produced by follicles. Samples from wild-type (W), heterozygous $\mathrm{K} 17^{+/-}(\mathrm{H})$, and homozygous null $\mathrm{K} 17^{-/}$ (N) are shown. No K17 antigen could be detected in samples prepared from $\mathrm{K} 7^{-/-}$mice, irrespective of the strain background (data not shown; see $B$ ). In addition to the K16 blot, a Coomassie blue staining (CB) of these proteins extracts is shown. Lane $M$ refers to mass markers (120 and $40 \mathrm{kD}$ bands identified). At this age, the appearance of the $\mathrm{C} 57 \mathrm{Bl} / 6$ $\mathrm{K} 17^{-/-}$mice has significantly normalized, while the 129 SV $\mathrm{K} 7^{-/-}$remain nonphenotypic. Remarkably, the levels of K16 antigen are dramatically increased

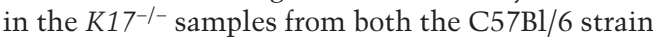
and the $129 \mathrm{~Sv}$ strain. Increased K16 levels are also

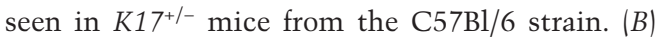
Similar analyses conducted on samples harvested from 14-day-old mice, which correspond to the first hair being produced by follicles. The identity of the primary antibody used is indicated at left. Monoclonal antibody AE13 recognizes hard type I kerat-

ins and is used as loading control. Lane $P$ refers to purified recombinant K17 or K16 proteins in the relevant blots. In the $129 \mathrm{~Sv}$ strain, which remain nonphenotypic, K16 levels are dramatically elevated in null hair clippings compared to heterozygous or wild-type samples. The extent of K16 induction is similar to that seen for the second hair produced (see $A$ ). In the C56Bl/6 strain, which displays a striking alopecia phenotype, K16 levels are only modestly increased in both $\mathrm{K}^{-7^{+/-}}$and $\mathrm{K} 17^{-/-}$hair clippings relative to wild-type. $(C, D)$ Visualization of the distribution of K16 antigen by indirect immunofluorescence in the hair bulb region of $K 17^{+/-}$and $K 17^{-/-}$ paraffin-embedded $7 \mathrm{~d}$ mouse back skin. Bar, $50 \mu \mathrm{m}$ and applies for $B$ and $C$. (E) Western analysis of total protein extracts prepared from nail clippings from adult mice in the original mixed genetic background (see Materials and Methods). Again, here, AE13 is used as a loading control. K16 levels are slightly higher in $\mathrm{K} 17^{-/-}$samples compared to $\mathrm{K} 17^{+/-}$and $\mathrm{K} 17^{+/+}$samples, whereas no consistent change is seen in the levels of K14 antigen.

Finally, we examined other epithelial appendages to determine whether $\mathrm{K} 16$ or the related K14 could account for the absence of a phenotype. In normal nail tissue, K17 can be easily found in the matrix, nail bed, and proximal nail fold (McGowan and Coulombe 2000). Yet, nail histology seem normal in $\mathrm{K} 17^{-/-}$mice, irrespective of the presence of a hair phenotype or strain background (data not shown). The levels of K16 antigen are slightly elevated in protein extracts prepared from $\mathrm{K} 17^{-/-}$nail clippings compared to controls (Fig. 5E). Given the lack of lesions in the nail, we cannot determine whether this increase, which is modest relative to that seen in hair (Fig. 5A,B), plays a protective role (see Discussion). In nail tissue sections prepared from phenotypic $\mathrm{K}^{-7^{-/}}$ mice, moreover, the K16 antigen remains restricted to the proximal nail fold and the nail bed, as is the case for control mice (data not shown). In eccrine sweat glands, $\mathrm{K} 17$ is normally expressed in the myoepithelial layer at the periphery of the glandular acini as well as in duct tissue (McGowan and Coulombe 1998a). Again, here, no anomaly can be seen in sweat gland histology in phenotypic $\mathrm{K}^{17^{-/-}}$mice (Fig. 6, cf. A and B). In this case, the staining intensity for K14 is significantly increased in the myoepithelial layer of $K 17^{-/-}$samples compared to controls (Fig. 6, cf. C and D with E), but no change occurred in K16 levels or distribution (data not shown). These observations add to the notion that, soon after birth, the consequences of the K17 null mutation are likely subject to modulation by related type I keratins. The variable penetrance of the hair phenotype in $\mathrm{K} \mathrm{7}^{-/-}$ mice correlates with a strain-dependent increase in K16 in hair precursor cells. Our data suggest but do not prove that in sweat glands, K14 and possibly other type I keratins account for the lack of detectable alterations in $\mathrm{K} 17^{-/-}$mice.

\section{Discussion}

Nullifying the mouse K17 gene profoundly interferes with the emergence of the hair coat, which normally occurs between days 3 and 7 after birth. When compensatory mechanisms are absent or insufficient, $\mathrm{K}^{17^{-/}}$ hairs are mechanically fragile, and this correlates with histological and ultrastructural defects in the medulla, matrix, and outer root sheath compartments. Our findings establish that $\mathrm{K} 17$ fulfills two important functions during the postnatal maturation of hair follicles: that of contributing to the mechanical resilience of the hair shaft itself, and that of promoting the viability of hairproducing epithelial cells, including the matrix. Correlating with the onset of the first postnatal anagen phase of the hair cycle at three weeks after birth, however, phenotypic recovery. This indicates that the role of K17 even the most severely affected K17 null mice undergo 


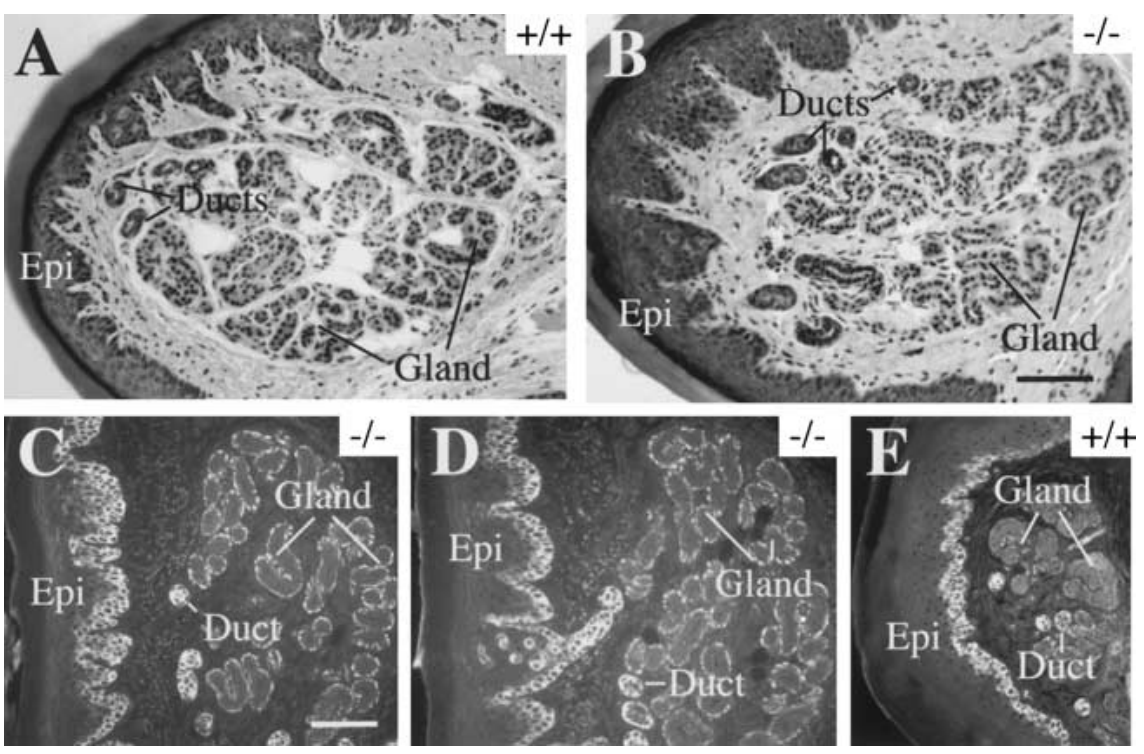

Figure 6. Plain histology and K14 indirect immunofluorescence of eccrine sweat glands as seen in sections prepared from paraffin-embedded adult paw tissue. In hematoxylin/eosin-stained preparations, the morphology of sweat gland appears indistinguishable in wild-type $(A)$ and $K 17^{-/-}$ mice $(B)$. In this tissue, the K17 antigen normally occurs in the myoepithelial layer of the glandular acini as well as in the sweat gland ducts (McGowan and Coulombe 1998). Surprisingly, the staining intensity for K14 is much increased in the myoepithelial layer surrounding glandular acini (gland) in $K 17^{-/-}$samples $(C, D)$ compared to controls $(E)$. The ducts and the basal layer of epidermis (Epi) are also immunopositive for K14, but no significant difference is seen between null and wildtype. No change is seen in the distribution or intensity of K16 immunostaining (data not shown). Bar in $B, 100 \mu \mathrm{m}$ and applies for $A$; bar in $C, 100 \mu \mathrm{m}$ and applies for $D$ and $E$. becomes less critical in the adult cycling hair, and/or that powerful compensatory mechanisms come into play. In that regard, increased levels of the related type I keratin 16 likely represent a key mechanism modulating the impact of the K17 allele on hair follicle tissue.

During the early stages of hair development, K17 appears to be present in nearly all cells within the placodes and primary hair germs (McGowan and Coulombe 1998). As the hair tissue matures further, however, K17 protein is maintained in the outer root sheath and the matrix of the bulb but otherwise persists in a detectable form only in the medulla of the differentiated hair shaft (McGowan and Coulombe 2000; this study). We show here that its absence translates into the acute fragility of the first hair shaft produced by postnatal follicles, albeit in a straindependent fashion. This points to an important contribution of the medulla compartment to the mechanical resilience of the first hair produced, or alternately, to a crucial role for K17-containing filaments in scaffolding the assembly of the differentiation-specific keratins expressed in the hair cortex and/or the inner root sheath layers. The fragile state of the K17 null hair is first revealed around the time of its emergence at the skin surface at $\sim 4-5 \mathrm{~d}$ after birth, when bending stress becomes significant. Other issues yet to be resolved are the mechanism(s) responsible for the shorter length of hair follicles and the massive apoptosis seen in all major compartments making up the follicle including the matrix of the hair bulb in phenotypic $K 17^{-/-}$mice. Whether these are a consequence of the hair fragility as well, or reflect a distinct function for K17 in the hair follicle, is unknown. In preliminary studies, we find that mechanically stressing the external fur in 13-14-day-old C57Bl/6 mice fails to enhance the frequency of apoptosis in hair tissue, suggesting that hair fragility and apoptosis are distinct phenomena. It is worth noting that null muta- tions in K14 (Lloyd et al. 1995), K5 (Peters et al. 2001), which each causes severe epidermal fragility, or in $K 6$ isoform genes (Wong et al. 2000), which severely fragilize the oral mucosa, do not cause apoptosis of keratinocytes. On the other hand, hepatocytes lacking K8-K18 filaments are more susceptible to TNF- $\alpha$-dependent (Caulin et al. 2000) and Fas-dependent (Gilbert et al. 2001) apoptosis and liver damage. Whether K17 promotes the survival of matrix epithelial cells in the hair bulb by influencing the flow through a specific signaling pathway is an intriguing possibility that awaits further investigation.

$\mathrm{K} 16$ protein is induced in hair tissue in response to the K17 null mutation, a consistent finding, and this correlates with a mitigation of the alopecia condition. The available evidence suggests that this induction is a complicated phenomenon. First, the steady-state level of K16 protein in the hair that has already emerged beyond the skin surface (our experiments made use of hair clippings) is only a partial indicator of its susceptibility to the effects of the K17 allele. The amplitude of this induction relative to controls represents a better predictor of the phenotype of K17 null mice, suggesting that its timing relative to the anagen phase, during which the hair shaft is being produced, may be critical. Second, the induction of K16 protein varies in amplitude between strains of mice and between cycles of hair production in at least some strains (e.g., C57Bl/6 strain). Based on the data obtained when backcrossing the K17 null allele into the C57Bl/6 inbred strain over six generations, it appears that the mechanism(s) involved in the induction of K16 in K17 null hair tissue is extrinsic to the locus /the mouse K16 and K17 genes are contiguous and separated by only $6 \mathrm{~kb}$; K. Bernot, K. McGowan, and P.A. Coulombe, in prep.). Moreover, the induction of K16 in $\mathrm{K} 17^{-/-}$hair tissue takes place in the absence of similar 
changes for $\mathrm{K} 6$, arguing that the mechanism(s) involved is distinct from the transcriptional coinduction exhibited by these two genes when "soft" epithelia (e.g., epidermis, oral mucosa, cornea) are challenged or diseased (e.g., Paladini et al. 1996; K. Bernot, K. McGowan, and P.A. Coulombe, in prep.). Additional studies will be required to pinpoint the mechanism(s) involved, determine the ultimate role of $\mathrm{K} 16$ induction in modulating this phenotype, and establish whether other mechanisms contribute as well. Meanwhile, it appears that the function(s) of K17 in this hard tissue can be fulfilled to a significant degree by K16. Not as firmly established by our data is a similar role for $\mathrm{K} 14$, although in a different epithelial context (e.g., the myoepithelium of sweat glands). Such a compensatory induction of related keratins in K17 null skin tissue has two major implications at this juncture. First, it adds to a growing body of experimental evidence demonstrating functional redundancy within the keratin superfamily (Ness et al. 1998; Paladini and Coulombe 1999; Hesse et al. 2000; Reichelt et al. 2001; Wojcik et al. 2001; Coulombe and Omary 2002). Second, this phenomenon provides insights into possible mechanism(s) underlying the heterogeneous clinical presentation of patients whose genomes harbor missense K17 alleles.

There is a wealth of information describing the clinical presentation of patients suffering the consequences of known missense $K 17$ alleles. All of the mutations discovered to date (see Smith et al. 2001 and references therein) map to a small region within the K17 coding sequence (the subdomain 1A within the $\alpha$-helical rod), and yet the clinical presentation of these patients varies considerably. As an extreme example, the same mutation, Arg94 $\rightarrow$ Cys (Covello et al. 1998), which affects a hot spot codon among type I keratin genes, give rise to two distinct clinical entities. Type 2 pachyonychia congenita is a disorder named after the nail dystrophy that characterizes it, but which affects several types of epithelial appendages to a varying degree (Irvine and McLean 1999). Steatocystoma multiplex, on the other hand, is typified by the presence of large subcutaneous cysts believed to evolve from sebaceous glands, and shows no nail involvement (Irvine and McLean 1999). Hair follicle anomalies occur in both these syndromes, although they vary widely in both type and frequency. For instance, pili torti is a clinical hallmark of type 2 pachyonychia congenita, whereas significant alopecia is seen only in a subset of patients (Clementi et al. 1986; Feinstein et al. 1988; Templeton and Wiegand 1997). The $\mathrm{K} 17^{-/-}$mice we report here show a spectacular yet straindependent alopecia that is not accompanied by detectable changes in sebaceous and sweat glands, or in the nail. A better understanding of the basis for the differences between this mouse model and human patients, particularly at the level of the nail and glands, requires further studies. In particular, replacement studies involving the tissue-specific expression of missense K17 alleles in the mouse $K 17^{-/-}$background may help determine whether individual features of pachyonychia congentia and/or steatocystoma multiplex represent loss-of- or gain-of-function phenotypes. Based on the findings reported here, however, one may speculate that the symptomatic variability observed in the human population reflects genetic heterogeneity in the steady-state levels or in the inducibility of related type I keratin genes (e.g., $\mathrm{K} 14, \mathrm{~K} 16)$ in K17-expressing cells and tissues. Examining this possibility in the general human population as well as in patients would be a worthwhile endeavor.

As is the case for many other keratin genes (Coulombe and Omary 2002), differential regulation of K17 gene expression is first seen at an early stage of epithelial morphogenesis (McGowan and Coulombe 1998a), and yet there is no obvious defect in the differentiation of the cell types concerned. That is, there is as of yet no direct evidence showing a role for specific keratin proteins in either promoting or maintaining a differentiated state (Coulombe and Omary 2002). The rationale for the tightly regulated expression of keratin genes in a differentiation-related fashion, which is conserved across species, remains an open and challenging question.

\section{Materials and methods}

\section{Construction of targeting vector and generation of K17 null mice}

Plasmid NeoTKXho, with functional PGK-Neo (Neo) and MC1TK (TK) cassettes for double selection, was used to generate the targeting vector (Wong et al. 2000). The $5^{\prime}$ arm of homology is a $3.0 \mathrm{~Kb}$ Aat II-EcoRI fragment derived from the 5' upstream regulatory region of the mouse K17 gene (McGowan and Coulombe 1998b). The $3^{\prime}$ arm of homology is a $4.5 \mathrm{~Kb} \mathrm{XbaI}$ fragment that begins at the $3^{\prime}$ end of exon 5 (in this instance the $X b a I$ site is derived from the phage vector) and extends through the $3^{\prime}$ noncoding region of the gene. The targeting vector (Fig. 1A) was linearized at a unique NotI site and transfected $(20 \mu \mathrm{g})$ by electroporation into $2 \times 10^{7}$ exponentially growing $129 / \mathrm{Sv}$ CK35 ES cells (Kress et al. 1998). ES cells were screened for G418 (GIBCO) and gancyclovir (Syntex Research) resistance for $10 \mathrm{~d}$ and genotyped. ES cells exhibiting the correct targeting event were injected into $\mathrm{C} 57 \mathrm{Bl} / 6$ blastocysts and transferred into (C57Bl/6xCBA)F1 pseudopregnant females. Chimeric males, identified by their agouti coat color, were mated with (C57Bl/6xDBA2)F1 females, and the resulting mice heterozygous for the disrupted $\mathrm{K} 17$ allele were interbred to obtain the $K 17^{-1-}$ mice. For genotyping, genomic DNA was extracted from mouse tails, digested with AseI and EcoRV (5' side of K17 locus) or XbaI (3' side of the locus), electrophoresed, and transferred onto nylon membrane (Gene Screen Plus; NEN Life Science Products) for Southern blotting. Random labeled probes were generated from cloned DNA fragments from the $5^{\prime}$ and 3 ' side of the locus (see Fig. 1A), respectively. During the ES cell screening phase, the Southern blot data were validated by PCR reactions making use of oligonucleotide primers located inside and outside the targeted locus to confirm homologous recombination.

\section{Breeding experiments}

To transfer the disrupted $K 17$ allele into the $129 / \mathrm{Sv}$ inbred strain background (Kress 1998), chimeric male mice (129/Sv $\times$ C57Bl/6) were crossed with wild-type 129/Sv female mice. Agouti coat-color offspring were screened for the presence of the allele. For transfer into the $\mathrm{C} 57 \mathrm{Bl} / 6$ inbred strain background 
(Jackson Labs), male and female $K 17^{+/-}$mice obtained in the original mixed strain background were mated for six successive generations with wild-type $\mathrm{C} 57 \mathrm{Bl} / 6$ mice of the opposite sex. In both instances, mice heterozygous for the disrupted K17 allele were interbred to obtain $\mathrm{K}^{-7^{--}}$mice.

\section{RNA analyses}

RNA was isolated from back skin tissue using Trizol Reagent (Life Technologies) and quantitated. For Northern blot analyses (Wong et al. 2000), $10 \mu \mathrm{g}$ of RNA was resolved by formaldehydeagarose gel electrophoresis, transferred to GeneScreen nylon membrane, and probed with a 400-bp fragment specific for the $3^{\prime}$ noncoding region of the $K 17$ transcript. After radioautographic exposure, the membrane was stripped and reprobed using a 692-bp fragment corresponding to the $\mathrm{Neo}^{\mathrm{r}}$ coding sequence (Wong et al. 2000).

\section{Primary antibodies}

Primary antibodies used include rabbit polyclonal antisera directed against K6 and K17 (McGowan and Coulombe 1998a), K16 (K. Bernot, K. McGowan, and P.A. Coulombe, in prep.), K5 (Lersch et al. 1989), K14 and K15 (Lloyd et al. 1995), and mouse monoclonal antibodies to hair type I keratins (AE13; Lynch et al. 1986) and to K10 (Sigma Chemicals).

\section{Western blot analyses}

Hair clippings were harvested from the back skin of 14-day-old and 33-35-day-old mice, and total proteins were extracted as described (McGowan and Coulombe 2000). Similarly, nail clippings were obtained from adult mice, and total proteins were extracted as described (Lynch et al. 1986). Protein concentrations were determined using a Bradford Assay Kit (Bio-Rad). Equal amounts of protein were electrophoresed in $8.5 \%$ SDSPAGE gels and electroblotted onto Protran nitrocellulose (Schleicher and Schuell). Bound primary antibodies were detected using enhanced chemiluminescence (Amersham Pharmacia Biotech) or alkaline phosphatase (Bio-Rad) as described by the manufacturers.

\section{Morphological studies}

For histology, tissues were fixed in Bouin's overnight at $4^{\circ} \mathrm{C}$ prior to paraffin embedding. Five- $\mu \mathrm{m}$ sections were stained with hematoxylin and eosin. Alternatively, they were immunostained using the primary antibodies described above and a peroxidase-based detection method or indirect immunofluorescence using FITC-conjugated probes (Kirkegaard and Perry Labs). TUNEL staining was performed on $4 \%$ paraformaldehyde-fixed, paraffin-embedded skin samples according to the manufacturer's instructions (Roche Molecular Biochemicals). For transmission electron microscopy, backskin from 5-day-old mice was fixed in $2 \%$ glutaraldehyde- $1 \%$ paraformaldehyde in $0.1 \mathrm{M}$ cacodylate buffer, $\mathrm{pH} 7.2$, postfixed in aqueous osmium tetroxide, and embedded in epoxy resin as described (Paladini and Coulombe 1999). Thin sections were cut, counterstained with uranyl acetate and lead citrate, and examined using a Philips CM120 electron microscope. For hair analyses involving a LEO surface scanning electron microscope, hair samples were prepared as described (Sundberg et al. 2000).

\section{Other hair analyses}

A large number of hairs were harvested by pulling them from the back of 14-d- and 54-day-old mice $(n=2)$ for each of the
$\mathrm{K} 17^{+/+}, \mathrm{K} 17^{+/-}$, and $\mathrm{K} 17^{-/-}$genotypes. To assess the frequency of individual hair types (zigzag, guard, awl, auchene; see Sundberg and Hogan 1994), at least 200 plucked hairs were counted and scored per mouse. To assess mechanical resilience, individual intact zigzag hairs $(n=20)$ were isolated from two $\mathrm{K} 7^{+/-}$and two phenotypic $\mathrm{K} \mathrm{7}^{-/-}$mice using a dissecting microscope, their bases (bulb region) secured firmly onto a glass slide using double-stick tape, and a firm pull applied from their other extremity (tip) using forceps. Hair breakage was assessed using the dissecting microscope.

\section{Acknowledgments}

We thank Drs. Elaine Fuchs (Chicago, IL) and Henry Sun (New York, NY) for providing antibodies, Dr. John Sundberg (Bar Harbor, ME) for his expertise on hair, and lab members for advice and support. K.M. was supported by an NRSA fellowship from the National Cancer Institute. These studies were supported by grant AR44232 (P.A.C.) from the National Institutes of Arthritis, Musculoskeletal and Skin Diseases (USA) and from the Centre National de la Recherche Scientifique and Institut Pasteur (C.B.; France).

The publication costs of this article were defrayed in part by payment of page charges. This article must therefore be hereby marked "advertisement" in accordance with 18 USC section 1734 solely to indicate this fact.

\section{References}

Baribault, H., Penner, J., Iozzo, R.V., and Wilson-Heiner, M. 1994. Colorectal hyperplasia and inflammation in keratin 8-deficient FVB/N mice. Genes \& Dev. 8: 2964-2973.

Caulin, C., Ware, C.F., Magin, T.M., and Oshima, R.G. 2000. Keratin-dependent, epithelial resistance to tumor necrosis factor-induced apoptosis. J. Cell Biol. 149: 17-22.

Clementi, M., Cardin de Stefani, E., Dei Rossi, C., Avventi, V., and Tenconi, R. 1986. Pachyonychia Congenita Jackson Lawler type: A distinct malformation syndrome. Br. J. Dermatol. 114: 367-370.

Coulombe, P.A. and Omary, M.B. 2002. Hard and soft principles defining the structure, function and regulation of keratin intermediate filaments. Curr. Opin. Cell Biol. 14: 110-122.

Covello, S.P., Smith, F.J., Sillevis Smitt, J.H., Paller, A.S., Munro, C.S., Jonkman, M.F., Uitto, J., and McLean, W.H. 1998. Keratin 17 mutations cause either steatocystoma multiplex or pachyonychia congenita type 2. Br. J. Dermatol. 139: 475480.

Feinstein, A., Friedman, J., and Schewach, M. 1988. Pachyonychia congenita. J. Am. Acad. Dermatol. 19: 705-711.

Fuchs, E. and Cleveland, D.W. 1998. A structural scaffolding of intermediate filaments in health and disease. Science. 279: 514-519.

Fuchs, E., Merrill, B.J., Jamora, C., and R. DasGupta. 2001. At the roots of a never-ending cycle. Dev. Cell. 1: 13-25.

Gat, U., DasGupta, R., Degenstein, L., and E. Fuchs. 1998. De novo hair follicle morphogenesis and hair tumors in mice expressing a truncated beta-catenin in skin. Cell 95: 605614.

Gilbert, S., Loranger, A., Daigle, N., and Marceau, N. 2001. Simple epithelium keratins 8 and 18 provide resistance to Fas-mediated apoptosis. The protection occurs through a receptor-targeting modulation. J. Cell Biol. 154: 763-774.

Grachtchouk, M., Mo, R., Yu, S., Zhang, X., Sasaki, H., Hui, C.C., and Dlugosz, A.A. 2000. Basal cell carcinomas in mice overexpressing Gli2 in skin. Nat. Genet. 24: 216-217. 
Hesse, M., Franz, T., Tamai, Y., Taketo, M.M., and Magin, T.M. 2000. Targeted deletion of keratins 18 and 19 leads to trophoblast fragility and early embryonic lethality. $E M B O J$. 19: 5060-5070.

Hesse, M., Magin, T.M., and Weber, K. 2001. Genes for intermediate filament proteins and the draft sequence of the human genome: Novel keratin genes and a surprisingly high number of pseudogenes related to keratin genes 8 and 18. $J$. Cell Sci. 114: 2569-2575.

Irvine, A.D. and McLean, W.H. 1999. Human keratin diseases: The increasing spectrum of disease and subtlety of the phenotype-genotype correlation. Br. J. Dermatol. 140: 815-828.

Jiang, C.K., Flanagan, S., Ohtsuki, M., Shuai, K., Freedberg, I.M., and Blumenberg, M. 1994. Disease-activated transcription factor: Allergic reactions in human skin cause nuclear translocation of STAT-91 and induce synthesis of keratin K17. Mol. Cell. Biol. 14: 4759-4769.

Kress, C., Vandormael-Pournin, S., Baldacci, P., Cohen-Tannoudji, M., and Babinet, C. 1998. Nonpermissiveness for mouse embryonic stem (ES) cells derivation circumvented by a single backcross to 129/Sv strain: Establishment of ES cell lines bearing the Omd conditional mutation. Mamm. Genome. 9: 998-1001.

Leigh, I.M., Navsaria, H., Purkis, P.E., McKay, I.A., Bowden, P.E., and Riddle, P.N. 1995. Keratins (K16 and K17) as markers of keratinocyte hyperproliferation in psoriasis in vivo and in vitro. Br. J. Dermatol. 133: 501-511.

Lersch, R., Stellmach, V., Stocks, C., Giudice, G., and Fuchs, E. 1989. Isolation, sequence, and expression of a human keratin K5 gene: Transcriptional regulation of keratins and insights into pairwise control. Mol. Cell. Biol. 9: 3685-3697.

Lloyd, C., Yu, Q.C., Cheng, J., Turksen, K., Degenstein, L., Hutton, E., and Fuchs, E. 1995. The basal keratin network of stratified squamous epithelia: Defining K15 function in the absence of K14. J. Cell Biol. 129: 1329-1344.

Lynch, M.H., O'Guin, W.M., Hardy, C., Mak, L., and Sun, T.T. 1986. Acidic and basic hair/nail ("hard") keratins: Their colocalization in upper cortical and cuticle cells of the human hair follicle and their relationship to "soft" keratins. J. Cell Biol. 103: 2593-2606.

Ma, L., Yamada, S., Wirtz, D., and Coulombe, P.A. 2001. A 'hot-spot' mutation alters the mechanical properties of keratin filament networks. Nat. Cell Biol. 3: 503-506.

Markey, A.C., Lane, E.B., Macdonald, D.M., and Leigh, I.M. 1992. Keratin expression in basal cell carcinomas. Br. J. Dermatol. 126: 154-160.

McGowan, K., and Coulombe, P.A. 1998a. Onset of keratin 17 expression coincides with the definition of major epithelial lineages during mouse skin development. J. Cell Biol. 143: 469-486.

McGowan, K.M., and Coulombe, P.A. 1998b. The wound repair associated keratins 6, 16, and 17: Insights into the role of intermediate filaments in specifying cytoarchitecture. In Subcellular biochemistry: Intermediate filaments. (eds. J.R. Harris and H. Herrmann), pp. 141-165. Plenum Publishing, London, UK.

McGowan, K.M. and Coulombe, P.A. 2000. Keratin 17 expression in the hard epithelial context of the hair and nail, and its relevance for the pachyonychia congenita phenotype. I. Invest. Dermatol. 114: 1101-1107.

Ness, S.L., Edelmann, W., Jenkins, T.D., Liedtke, W., Rustgi, A.K., and Kucherlapati, R. 1998. Mouse keratin 4 is necessary for internal epithelial integrity. J. Biol. Chem. 273: 23904-23911.

Oro, A.E. and Scott, M.P. 1998. Splitting hairs: Dissecting roles of signaling systems in epidermal development. Cell. 95:
$575-578$.

Paladini, R.D. and Coulombe, P.A. 1999. The functional diversity of epidermal keratins revealed by the partial rescue of the keratin 14 null phenotype by keratin 16. J. Cell Biol. 146: $1185-1201$.

Paladini, R.D., Takahashi, K., Bravo, N.S., and P.A. Coulombe. 1996. Onset of re-epithelialization after skin injury correlates with a reorganization of keratin filaments in wound edge keratinocytes: Defining a potential role for keratin 16 I. Cell Biol. 132: 381-397.

Paus, R. and Cotsarelis, G. 1999. The biology of hair follicles. New Engl. J. Med. 341: 491-497.

Peters, B., Kirfel, J., Bussow, H., Vidal, M., and Magin, T.M. 2001. Complete cytolysis and neonatal lethality in keratin 5 knockout mice reveal its fundamental role in skin integrity and in epidermolysis bullosa simplex. Mol. Biol. Cell. 12: $1775-1789$.

Proby, C.M., Churchill, L., Purkis, P.E., Glover, M.T., Sexton, C.J., and Leigh, I.M. 1993. Keratin 17 expression as a marker for epithelial transformation in viral warts. Am. J. Pathol. 143: $1667-1678$

Reichelt, J., Bussow, H., Grund, C., and Magin, T.M. 2001. Formation of a normal epidermis supported by increased stability of keratins 5 and 14 in keratin 10 null mice. Mol. Biol. Cell. 12: 1557-1568.

Sano, S., Kira, M., Takagi, S., Yoshikawa, K., Takeda, J., and Itami, S. 2000. Two distinct signaling pathways in hair cycle induction: Stat3-dependent and -independent pathways. Proc. Nat1. Acad. Sci. 97: 13824-13829.

Smith, F.J., Coleman, C.M., Bayoumy, N.M., Tenconi, R., Nelson, J., David, A., McLean, W.H. 2001. Novel keratin 17 mutations in pachyonychia congenita type 2. J. Invest. Dermatol. 116: 806-808.

Sundberg, J.P. and Hogan, M.E. 1994. Hair types and subtypes in the laboratory mouse. In Handbook of mouse mutations with skin and hair abnormalities (ed. J.P. Sunberg), pp. 5768. CRC Press, Boca Raton, FL.

Sundberg, J.P., Boggess, D., Sundberg, B.A., Eilertsen, K., Parimoo, S., Filippi, M., Stenn, K. 2000. Asebia-2J. (Scd1ab2J): A new allele and a model for scarring alopecia. Am. J. Pathol. 156: $2067-2075$

Takahashi, K., Yan, B., Yamanishi, K., Imamura, S., and Coulombe, P.A. 1998. The two functional keratin 6 genes of mouse are differentially regulated and evolved independently from their human orthologs. Genomics. 53: 170-183.

Templeton, S.F. and Wiegand, S.E. 1997. Pachyonychia congenita-associated alopecia. A microscopic analysis using transverse section technique. Am I. Dermatopathol. 19: 180-184.

Troyanovsky, S.M., Guelstein, V.I., Tchipysheva, T.A., Krutovskikh, V.A., and Bannikov, G.A. 1989. Patterns of expression of keratin 17 in human epithelia: Dependency on cell position. J. Cell Sci. 93: 419-426.

Woicik, S.M., Longley, D.R., and Roop, M.A. 2001. Discovery of a novel murine keratin $6(\mathrm{~K} 6)$ isoform explains the absence of hair and nail defects in mice deficient for K6a and K6b. J. Cell Biol. 154: 619-630.

Wong, P., Colucci-Guyon, E., Takahashi, K., Gu, C., Babinet, C., and Coulombe, P.A. 2000. Introducing a null mutation in the mouse $\mathrm{K} 6 \alpha$ and $\mathrm{K} 6 \beta$ genes reveals their essential structural role in the oral mucosa. J. Cell Biol. 150: 921-928. 


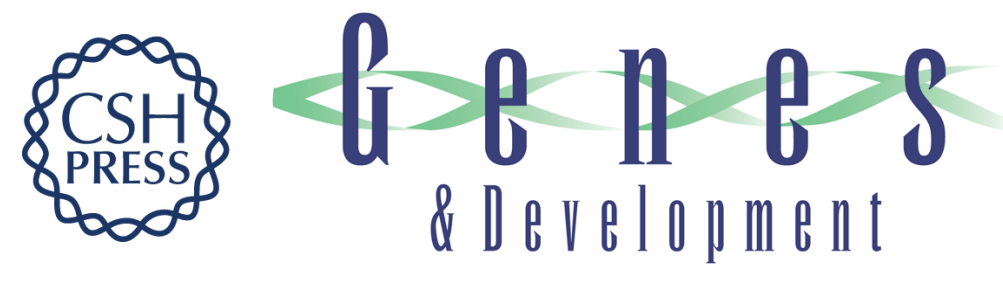

\section{Keratin 17 null mice exhibit age- and strain-dependent alopecia}

Kevin M. McGowan, Xuemei Tong, Emma Colucci-Guyon, et al.

Genes Dev. 2002, 16:

Access the most recent version at doi:10.1101/gad.979502

References This article cites 39 articles, 19 of which can be accessed free at: http://genesdev.cshlp.org/content/16/11/1412.full.html\#ref-list-1

License

Email Alerting Receive free email alerts when new articles cite this article - sign up in the box at the top Service right corner of the article or click here.

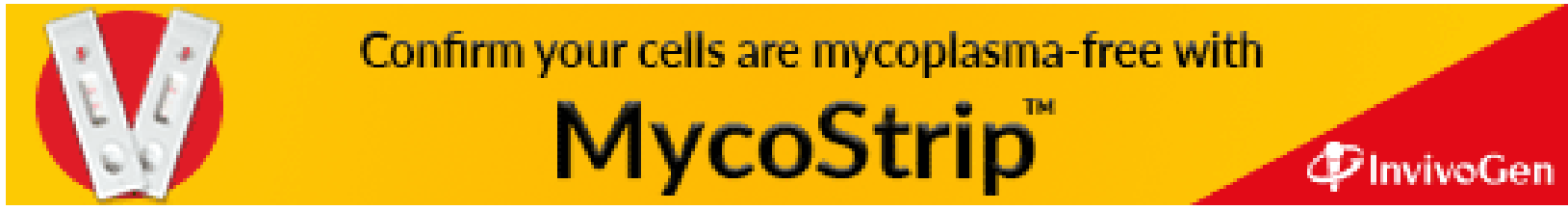

